\title{
Neutrophil immunodeficiency syndrome
}

INSERM

\section{Source}

INSERM. (1999). Orphanet: an online rare disease and orphan drug data base. Neutrophil immunodeficiency syndrome. ORPHA:183707

Neutrophil immunodeficiency syndrome is a primary immunodeficiency characterized by neutrophilia with severe neutrophil dysfunction, leukocytosis, a predisposition to bacterial infections and poor wound healing, including an absence of pus in infected areas. 